\title{
Kelayakan kualitas air kolam di lokasi pariwisata Embung Klamalu Kabupaten Sorong Provinsi Papua Barat
}

\section{(Feasibility of pond water quality in tourism area of Embung Klamalu Sorong Regency, West Papua)}

\author{
Rut Yullyn Yumame, Robert .Rompas, N. P. L. Pangemanan
}

\begin{abstract}
The purpose of research was to analyze water quality parameters including temperature, brightness, $\mathrm{pH}$, dissolved oxygen, alkalinity, and carbon dioxide in tourism area Embung Klamalu, Sorong Regency, West Papua Province. Measurement of water parameters was done in situ and in laboratory. It was found that on week two measurement, water temperature ranged from 27.2 to $28.9^{\circ} \mathrm{C}$ in the morning and 28.2 to $30.2^{\circ} \mathrm{C}$ in the afternoon; brightness from 6.0 to 0.7 and from 7.0 to $7.8, \mathrm{pH} 6.0$ to 6.8 and from 7.0 to 7.8 , DO from 6.10 to $7.35 \mathrm{mg} / \mathrm{L}$; total alkalinity $100-160 \mathrm{mg} / \mathrm{L}$ and $100-140 \mathrm{mg} / \mathrm{L}$, carbon dioxide 50.92 to $85.93 \mathrm{mg} / \mathrm{L}$ and 55.90 to $75.92 \mathrm{mg} / \mathrm{L}$. It was concluded that parameters of pond water in tourism area Embung Klamalu were still in suitable for aquaculture activity.
\end{abstract}

Keywords: water quality, pond, Embung Klamalu, Sorong Regency

\section{PENDAHULUAN}

Di Indonesia peran sektor pariwisata sangat penting dan telah menarik perhatian masyarakat dan pemerintah karena telah memberikan devisa bagi negara dan dapat mengurangi pengangguran di Indonesia. Khusus pariwisata perikanan (pemancingan ikan) yang ada di Provisi Papua Barat yang bertempat pada Waduk Embung Klamalu Distrik Aimas Kabupaten Sorong. Waduk Embung Klamalu adalah salah satu waduk yang memiliki potensi yang cukup besar untuk melakukan kegiatan budidaya, benih perikanan dan pertanian.Disamping itu juga pada lokasi tersebut didirikan tempat pariwisata. Agar pendapatan dan keuntungan dari pemilik lokasi pariwisata tersebut tidak hanya didapat dari setiap orang yang berkunjung untuk melakukan kegiatan memancing, tetapi juga didapat dari hasil membudidaya ikan.

Lokasi pariwisata pada Embung Klamalu Distrik Aimas yang cukup strategis, telah membuktikan sebagai salah satu alternatif untukmelakukan kegiatan perikanan (membudidayakan ikan), yang dapat diandalkan dalam meningkatkan kesejahteraan masyarakat Kabupaten Sorong (Dinas Perikanan, 2012). Selain untuk 
pariwisata pemancingan, tempat ini juga dijadikan sebagai tempat budidaya ikan air tawar. Adapun jenis ikan yang dibudidaya yaitu, ikan Mas, ikan lele, ikan Patin dan lain sebagainya dengan bentuk kolam sistem perkolaman. pertumbuhan terhambat, dan timbulnya hama penyakit.

Faktor-faktor pendukung yang berhubungan dengan budidaya perairan perlu diperhatikan antara lain, oksigen terlarut (DO), suhu, $\mathrm{pH}$, amoniak, dan lainlain. Sumber air yang diperlukan dalam kegiatan budidaya ikan harus memenuhi beberapa kriteria paremeter yang mendukung kualitas air. Hal tersebut meliputi sifat kimia dan fisika, yang meliputi suhu, kekeruhan, kecerahan, derajat keasaman $(\mathrm{pH})$, oksigen terlarut (DO), karbondioksida, BOD, alkalinitas total, fosfat $\left(\mathrm{PO}_{4}\right)$, nitrit $\left(\mathrm{NO}_{2}\right)$, nitrat $\left(\mathrm{NO}_{3}\right)$. Atas dasar uraian diatas timbul gagasan untuk mengadakan penelitian mengenai kelayakan kualitas air pada kolam pemancingan ikan di Lokasi Pariwisata Embung Klamalu Kabupaten Sorong.

\section{BAHAN DAN METODE}

\section{Teknik pengambilan sampel}

Lokasi pengambilan sampel air di Kolam Pariwisata Waduk Embung Klamalu Kabupaten Sorong, dilakukan pada tiga stasiun dengan Sembilan titik pengambilan, pada setiap titik dilakukan 2 pengulangan pada pagi hari pukul 08.00 dan sore hari pukul 16.00 WIT. Untuk titik pengamatan ditentukan berdasarkan beberapa parameter. Jarak pengambilan sampel air antara stasiun I ke stasiun II serta ke stasiun III masingmasing berjarak $\pm 20 \mathrm{~m}$. Pengambilan sampel pada setiap stasiun diambil pada tiga titik masing-masing berjarak $50 \mathrm{~m}$.

\section{Metode pengukuran}

Parameter air diukur dengan dua cara yaitu secara in situ dan analisis laboratorium. Parameter suhu, kecerahan, $\mathrm{pH}$, dan DO langsung di ukur di lapangan.(in situ), sedangkan alkalinitas total, dan karbondioksida $\left(\mathrm{CO}^{2}\right)$ di analisis di Laboratorium Akademik Perikanan Sorong (APSOR).

\section{Pengumpulan data dan analisis data}

Data yang dikumpulkan dalam penelitian ini adalah parameter kualitas air yang meliputi : suhu, $\mathrm{pH}$, kecerahan, DO, dan alkalinitas total, dianalisis secara deskriptif dengan mempertimbangkan faktor-faktor penentu kelayakan budidaya perairan dan dibandingkan dengan Baku Mutu air tawar peraturan pemerintah Nomor. 82 Tahun 2001 tentang pengelolaan Kualitas Airs Dan Pengendalian Pencemaran (kelas III), serta Kriteria- kriteria Budidaya Perairan Air Tawar.

\section{HASIL DAN PEMBAHASAN}

\section{Suhu}

Berdasarkan hasil penelitian dapat diperoleh kisaran suhu pada minggu pertama hari yang pertama dan kedua hasil penelitian yang di ambil pada pagi hari parameter suhu berkisar: $27,0-28,0{ }^{\circ} \mathrm{C}$ dan $27,0-28,{ }^{\circ} \mathrm{C}$, dan pada sore hari suhu berkisar $28,0-30,4^{\circ} \mathrm{C}$ dan $28,0-29,4^{\circ} \mathrm{C}$. Sedang hasil penelitian minggu II hari pertama dan kedua pada pagi hari suhu berkisar antara 27,2$28,9^{\circ} \mathrm{C}$ dan $27,4-28,8^{\circ} \mathrm{C}$. Menurut Baku 
Mutu air tawar Nomor. 82 Tahun 2001 tentang pengelolaan kualitas air, suhu untuk kegiatan budidaya ikan air tawar adalah devesit 3. Suhu di lokasi penelitian berada pada kisaran yang optimal. Untuk hasil penelitian suhu dilihat pada Gambar 1 .

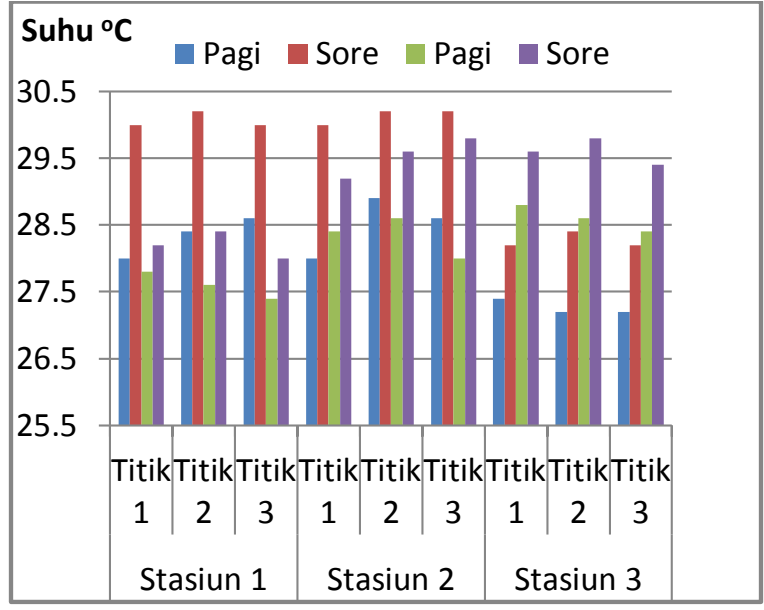

Gambar 1. Hasil pengukuran suhu air

Faktor- faktor yang mempengaruhi suhu antara lain: letak ketinggian dari permukaan laut, letak tempat terhadap garis edar matahari, musim, cuaca, waktu pengukuran, kedalaman air dan kegiatan manusia di sekitar perairan, misalnya kegiatan industri dan pemukiman (Sobur dalam Tumbol, 1991).

Asmawi (1987) menyatakan bahwa proses percernaan makanan yang dilakukan oleh ikan, berjalan sangat lambat pada suhu yang rendah, tetapi lebih cepat pada perairan yang suhu lebih tinggi. Suhu air yang optimal untuk selera makan ikan adalah antara $25^{\circ} \mathrm{C}-27^{\circ} \mathrm{C}$.Kisaran suhu perairan yang ideal bagi kehidupan ikan ialahtidak lebih besar dari $5^{0} \mathrm{C}$ (Asmawi, 1987).

\section{Kecerahan}

Berdasarkan hasil penelitian pada minggu II adalah kecerahan $15 \mathrm{~cm}$ dan 20 $\mathrm{cm}$, dan untuk sore hari kecerahan $15 \mathrm{~cm}$ dan $20 \mathrm{~cm}$. Untuk hasil penelitian kecerahan dilihat pada Gambar 2.

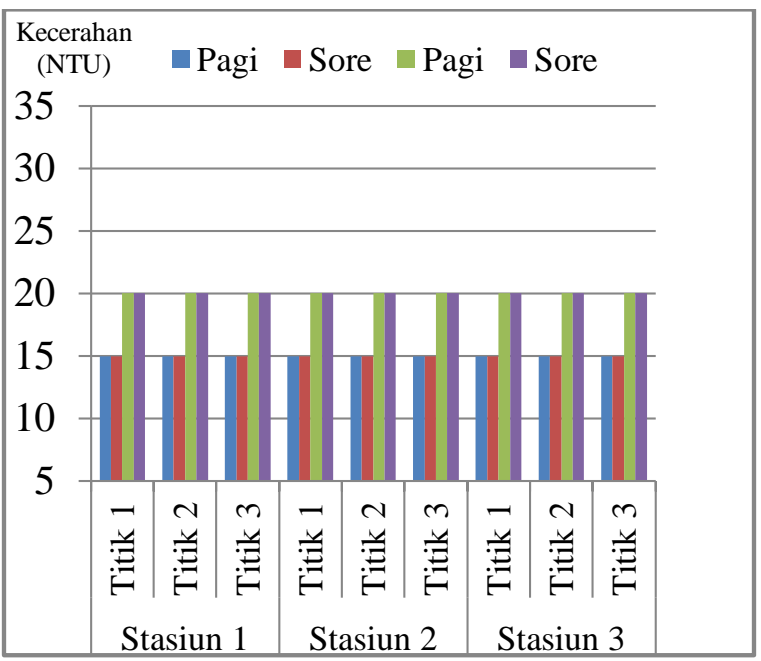

Gambar 3. Hasil pengukuran kecerahan air

Dengan mengetahui kecerahan suatu perairan, kita dapat mengetahui sampai dimana masih ada kemungkinan terjadi proses asimilasi dalam air, lapisan- lapisan manakah yang tidak keruh, yang agak keruh, dan yang paling keruh. Air yang tidak terlampau keruh dan yang tidak pula terlampau keruh, baik untuk kehidupan biota budidaya. Cahaya matahari merupakan sumber energi yang utama bagi kehidupan jasad termasuk kehidupan di perairan karena ikut menentukan produktivitas perairan. Intensitas cahaya matahari merupakan faktor abiotik utama yang sangat menentukan laju produktivitas primer perairan, sebagai sumber energi dalam proses fotosintesis (Boyd, 1982).

Umumnya fotosintesis bertambah sejalan dengan bertambahnya intensitas cahaya sampai pada suatu nilai optimum tertentu (cahaya saturasi), diatas nilai tersebut cahaya merupakan penghambat bagi 
fotosintesis (cahaya inhibisi). Sedangkan semakin ke dalam perairan intensitas cahaya akan semakin berkurang dan merupakan faktor pembatas sampai pada suatu kedalaman dimana fotosintesis sama dengan respirasi. Kedalaman perairan dimana proses fotosintesis sama dengan proses respirasi disebut kedalaman kompensasi. Kedalaman kompensasi biasanya terjadi pada saat cahaya di dalam kolom air hanya tinggal 1 \% dari seluruh intensitas cahaya yang mengalami penetrasi dipermukaan air.Kedalamankompensasi sangat dipengaruhi oleh kekeruhan dan keberadaan awan sehingga berfluktuasi secara harian dan musiman (Effendi, 2003).

Cahaya merupakan sumber energi utama dalam ekosistem perairan. Di perairan cahaya memiliki dua fungsi utama (Jeffries dan Mills, 1996 dalam Effendi, 2003) antara lain adalah :

1. Memanasi air sehingga terjadi perubahan suhu dan berat jenis (densitas) dan selanjutnya menyebabkan terjadinya percampuran massa dan kimia air. Perubahan suhu juga mempengaruhi tingkat kesesuaian perairan sebagai habitat suatu organisme akuatik, karena setiap organisme akuatik memiliki kisaran suhu minimum dan maksimum bagi kehidupannya.

2. Merupakan sumber energi bagi proses fotosintesis algae dan tumbuhan air. Kecerahan merupakan ukuran transparansi perairan, yangditemukan secara visual dengan menggunakan secchi disk. Nilai kecerahan dinyatakan dalam satuan meter, nilai ini sangat dipengaruhi oleh keadaan cuaca, waktu pengukuran, kekeruhan dan padatan tersuspensi serta ketelitian seseorang yang melakukan pengukuran. Pengukuran kecerahan sebaiknya dilakukan pada saat cuaca cerah (Effendi, 2003). Untuk budidaya perikanan laut, kecerahan air yang dipersyaratkan adalah $>3$.

\section{Derajat Keasaman (pH)}

Berdasarkan penelitian yang diperoleh pada minggu II, pH berkisar pH 6,0-6,8 dan 6,0-6,8 dan untuk sore hari $\mathrm{pH}$ berkisar 7,07,4 dan 7,0-7,8. Untuk hasil penelitian derajat keasaman $(\mathrm{pH})$ dapat dilihat pada Gambar 3.

Keasaman air $(\mathrm{pH})$ mempengaruhi tingkat kesuburan perairan. Perairan yang terlalu asam akan kurang produktif (Jangkura, 1984). Pada perairan yang banyak sampah ogranik terkomposisi dapat ditemukan $\mathrm{pH}$ rendah.Kehidupan hewan akuatik semakin terganggu apabila $\mathrm{pH}$ air makin jauh dari titik normal (Klein dalam Tumbol, 1991).

Sebagian besar organisme air bisa beradaptasi dengan nilai $\mathrm{pH}$ yang bervariasi namun tidak mudah bertahan dengan perubahan secara tiba-tiba dengan variasi yang besar.Air yang baik untuk pemeliharaan ikan adalah yang bersifat netral dan sedikit alkali dengan $\mathrm{pH}$ berkisar 7 sampai 8 (Huet, 1971). Pada air yang mempunyai pHrendah ikan-ikan akan meningkatkan produksilendirnya dan menjadi sangat sensitif terhadap infeksi bakteri (Landau, 1992). 


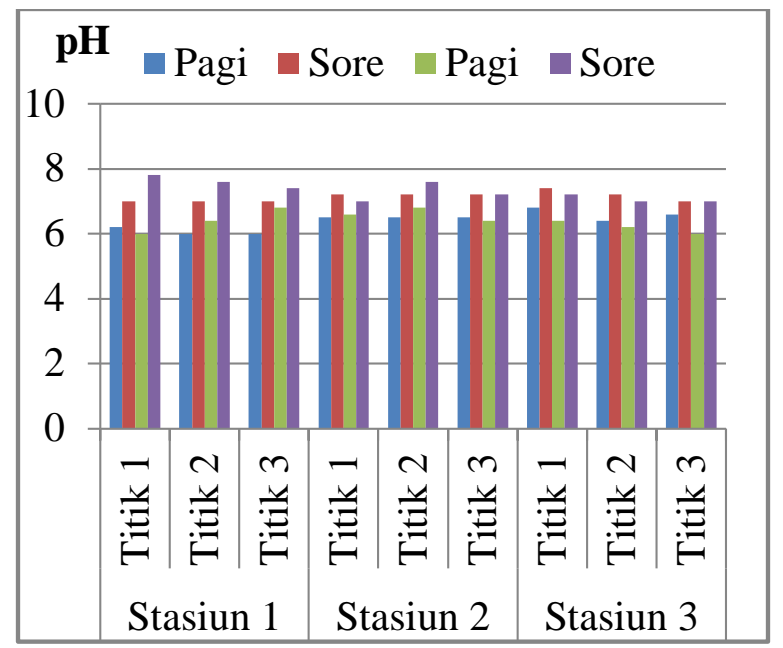

Gambar 3. Hasil pengukuran pH

Lingga (1990) menyatakan bahwa $\mathrm{pH}$ ideal untuk pemeliharaan ikan adalah 7,5-8,5. Namun begitu pH 6,5-9 masih dikategorikan baik untuk pemeliharaan ikan. Tetapi pH 4-11 akan mengakibatkan kematian bagi ikan.

\section{Oksigen Terlarut}

Berdasarkan penelitian DO di lokasi penelitian dan dibandingkan dengan Baku Mutu air Tawar Peraturan Pemerintah Nomor.82 Tahun 2001 tentang pengelolaan kualitas air, kisaran oksigen terlarut untuk kegiatan budidaya ikan yaitu > $3 \mathrm{mg} / \mathrm{l}$. Untuk budidaya ikan, nilai DO di lokasi penelitian masih layak untuk kegiatan budidaya ikan. Untuk hasil penelitian dilihat pada Gambar 4.

Oksigen terlarut (DO) untuk biota budidaya adalah $\pm 5 \mathrm{mg} / \mathrm{L}$. Apabila kurang akan menyebabkan stres pada ikan, kerentanan terhadap serangan parasit dan penyakit, bahkan kematian (Stickney, 1979). Hasil penelitian pada tiga stasiun dengan sembilan titik pengamatan, dimana DO tertinggi berada pada stasiun dua titik dua minggu pertama dengan nilai 8,03 mg/L sedangkan DO terendah terdapat pada stasiun tiga titik dua minggu pertama dengan nilai 6,61 mg/L (lihat gambar. 7) dengan kecenderungan nilai DO pada stasiun dua lebih rendah dibandingkan pada stasiun satu dan tiga hal ini diakibatkan pada stasiun satu dan tiga aliran air lebih kuat dibandingkan pada stasiun dua aliran air mulai terhambat dengan banyaknya jumlah karamba.

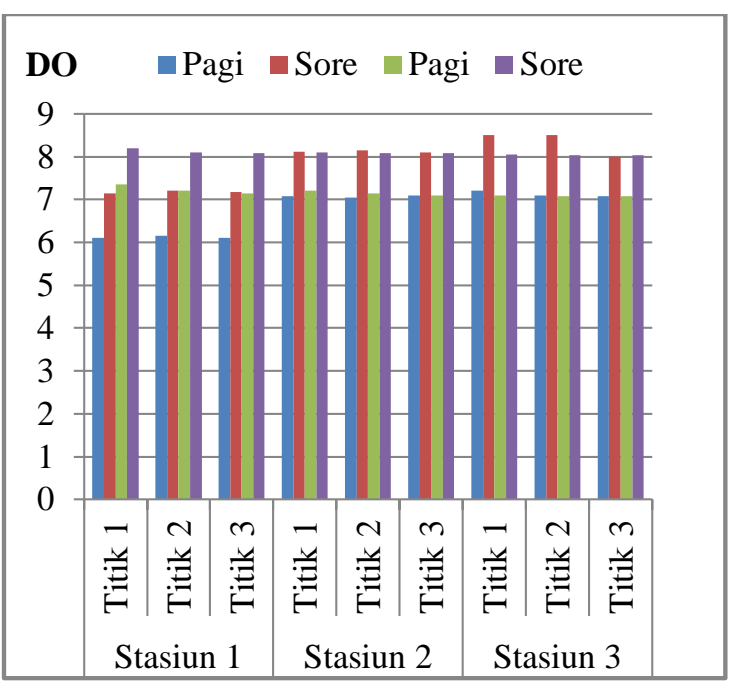

Gambar 4. Hasil pengukuran DO

Perbedaan derasnya aliran air mempengaruhi tingginya DO yang terdifusi.Oksigen terlarut dalam air melalui difusi oksigen dari atmosfir dan sebagian dari hasil fotosintesis (Stickney, 1979).Variasi nilai DO pada kisaran ini dipengaruhi juga oleh suhu. Kenaikan suhu menyebabkan penurunan kadar oksigen terlarut.

\section{Alkalinitas total}

Berdasarkan hasil penelitian pada minggu II didapat Alkalinitas total pagi hari berkisar 120-160 mg/l dan 100- 160 mg/l dan untuk sore hari 100- 120 mg/l dan 100$140 \mathrm{mg} / \mathrm{l}$. Nilai alkalinitas di perairan alami 
hampir tidak pernah melebihi 50mg/l $(\mathrm{ppm}) \mathrm{CaCO}_{3}$.Perairan dengan nilai alkalinitas yang terlalu tinggi tidak terlalu disukai oleh biota akuatik karena biasanya diikuti dengan nilai kesadahan yang tinggi atau kadar garam natrium yang tinggi .nilai alkalinitas yang baik berkisar antara 30-500 $\mathrm{mg} / \mathrm{l} \mathrm{CaCO}_{3}$. Nilai alkalinitas di perairan berkisar antara 5 hingga ratusanmg/l $\mathrm{CaCO}_{3}$.Nilai alkalinitas pada perairan alami adalah $40 \mathrm{mg} / \mathrm{CaCO}_{3}$ (Boyd, 1979).

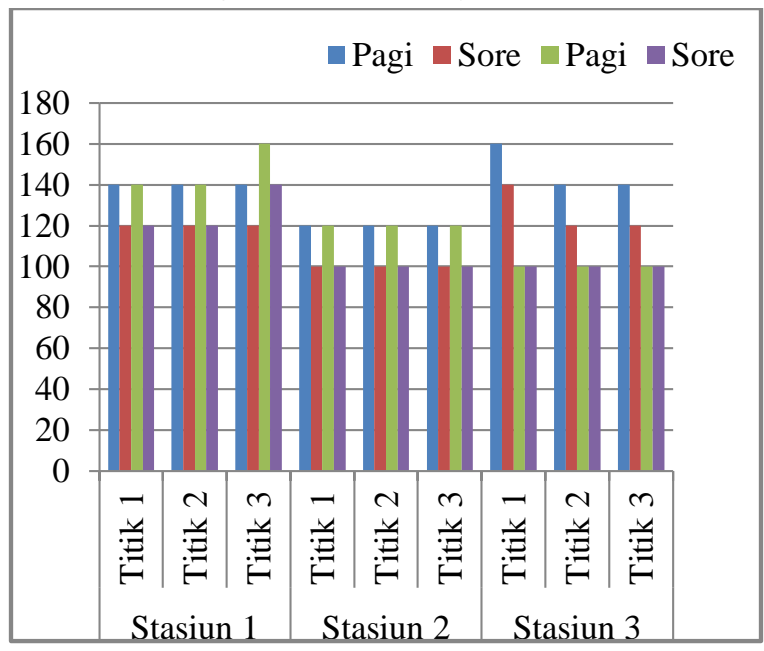

Gambar 5. Hasil pengukuran alkalinitas total

Untuk tumbuh optimal, plankton menghendaki total alkalinitas sekitar 80-120 $\mathrm{mg} / \mathrm{l} \mathrm{CaCO}_{3}$. Pada kisaran total alkalinitas kurang atau melebihi dari kisaran tersebut, pertumbuhan plankton terhambat. Namun, bukan berarti pertumbuhan plankton pasti optimal jika total alkalinitas air cukup. Hal inikarena masih banyak parameter kualitas air yang mempengaruhi pertumbuhan plankton, seperti ketersediaan $\mathrm{CO}_{2}$ dan pH.Alkalinitas dinyatakan dalam air $\mathrm{mg} / \mathrm{l}$ $\left(\mathrm{CaCO}_{3}\right)$, dalam air dapat bertindak sebagai Bufer (penyangga) $\mathrm{pH}$, dimana $\mathrm{pH}$ dalam basa membentuk ion karbonat melepaskan ion karbonat yang bersifat asam sehingga menjadi NETRAL.

\section{Karbon Dioksida}

Perairan air tawar alami hampir tidak pernah memiliki $\mathrm{pH}>9$ sehingga tidak ditemukan karbon dalam bentuk karbonat. Pada air tanah, kadar karbondiokdioksida biasanya sekitar 10mg/l karena sifat air tanah cenderung alkalis. Perairan yang memiliki kadar sodium tinggi mengandung karbonat sekitar 50mg/l. Perairan tawar air yang memiliki $\mathrm{pH} \quad 7-8$ biasanya mengandung ion karbonat $<500 \mathrm{mg} / \mathrm{l}$ dan hampir tidak pernah kurang dari $25 \mathrm{mg} / \mathrm{l}$. ion ini mendominasi sekitar 60-90\% bentuk karbon anorganik total diperairan. Kadar karbon dioksida sebesar 5-10 mg/l di dalam air masih dapat di toleraleransi oleh hewan air asalkan kadar oksigen nya cukup tinggi. Akan tetapi kadar karbondioksida 50-100 $\mathrm{mg} / \mathrm{l}$ dapat mematikan ikan dan udang dalam waktu lama, sedangkan kadar karbon dioksida 100-200 mg/175,92mg/l. Untuk hasil penelitian dilihat pada Gambar 7.

\section{KESIMPULAN}

Kualitas air kolam baik fisika maupun kimia di lokasi pariwisata Embung Kamalu layak untuk membudidayakan ikan.

\section{DAFTAR PUSTAKA}

Asmawi S. 1987. Pemeliharaan Ikan dalam Karamba. P.T. Gramedia Jakarta.

Baku Mutu, 2001. Peraturan Pemerintah No.

82 Tentang Pengelolaan Kualitas Dan Pengendalian Pencemaran Air.

Boyd CE, Lichkopper F. 1979. Water Quality Managemen in Pont Fish Culture. Auburn University 
Agricultural Experimental Station.

Alabama, USA.

Dinas Perikanan dan Kelautan Kabupaten Sorong, 2012. Laporan Akuntanbilitas Instansi Pemerintah (LAKIP). Kabupaten Sorong.

Effendi H. 2003.Telaah Kualitas Air BagiPengelolaan Sumberdaya dan Lingkungan Perairan.259 hal.

Huet M. 1971.Texs Boot of Fish Culture, Breeding and Cultivation of Fish. Fishing Ney Boot Ltd. Farnham, Survey. England.

Jangkaru Z. 1984. Pemeliharaan Ikan

Dalam Kolam Air Deras. CV

Yasaguna. Bogor.
Lingga P. 1990. Ikan Mas Kolam Air Deras. Penebar Swadaya. Jakarta.

Landau M. 1992.Introduction to Aquaculture, Jonh Weley \& Sons press. New York

Sticney. 1979. Principles of Warm Water Aquaculture.John Wiley and Sons, Inc. Toronto.

Tumbol RA. 1991. Pratelaah Ekologis Sungai-sungai di ManadoMinahasa dan Bitung.Skripsi Fakultas Perikanan UNSRAT Manado. 